\title{
LA NEOLOGIA: UN NOU CAMP A LA CERCA DE LA SEVA CONSOLIDACIÓ CIENTÍFICA
}

\author{
NEOLOGY, A NEX FIELD IN SEARCH \\ OF ITS SCIENTIFIC STABILIZATION
}

\author{
M. Teresa Cabré Castellví \\ Universitat Pompeu Fabra \\ teresa.cabre@upf.edu
}

Resum: En aquest text s'ofereix una panoràmica àmplia de la neologia com a camp de coneixement i com a camp de treball. Així mateix s'exploren les relacions que la neologia manté amb altres matèries com la psicologia i la sociologia, i les seves connexions amb les tecnologies. Els neologismes són l'objecte central de la neologia com a camp de coneixement. L'article mostra la dificultat de delimitar clarament aquest objecte per tal com es tracta d'un objecte relatiu, a més de polièdric. La relativitat dels neologismes obliga a definir-los sobre la base d'establir un punt de referència a partir del qual una unitat és neològica en funció de la producció, de la recepció o de la circulació social. L'article presenta també una sèrie de principis que si es respecten, podrien conduir a l'establiment de la neologia com un camp estructurat i estabilitzat entre els diversos camps del saber.

Paraules clau: neologia, disciplina, teoria, camp de coneixement, objecte científic, neologisme, epistemologia.

Abstract: This text provides a comprehensive overview of neology as both a field of knowledge and a field of work. It also explores the relationships between neology and other areas such as psychology and sociology, and its connections with technology. Neologisms are the central object of neology as a field of knowledge. The paper shows the difficulty of clearly defining this object because it is a relative as well as a polyhedral object. Because of the relativity of neologisms, we are obliged to define them on the basis of a reference point from which a unit could be considered new: depending on its production, its reception or its social circulation. The paper also presents a set of principles which, if respected, could lead to the establishment of neology as a structured and stabilized field among different fields of knowledge.

Key words: neology, science, theory, field of knowledge, scientific object, neologism, epistemology. 
És un fet natural que la distribució del saber en camps de coneixement i disciplines evolucioni permanentment. De fet, si revisem la història de les ciències des d'aquesta perspectiva, podrem constatar aquest fet. En la Grècia presocràtica el coneixement se centrava en la physis, però amb Sòcrates la filosofia es va orientar a aspectes més típicament relacionats amb l'ètica, la moral i la política. D'aleshores ençà s'han succeït una infinitat de segmentacions, cada una de les quals, producte d'una determinada manera d'entendre el coneixement i les seves pràctiques i reflex de l'evolució del pensament i la societat.

Per fer-se càrrec de la dinàmica del coneixement i de la seva parcel-lació només cal pensar com han evolucionat les ciències naturals en els darrers cinquanta anys: programes d'estudis com les ciències de la terra, les ciències del mar i les ciències del medi ambient són propostes molt recents; i matèries com l'ecologia o la nutrició es van incorporar com a disciplines autònomes durant la segona meitat del segle passat. Tot evoluciona, i la segmentació dels sabers no és cap excepció a aquest principi.

La neologia és un dels camps que ha sorgit amb força durant els darrers decennis. Ha sorgit amb força com a disciplina, com a saber diferenciat i autònom, cosa que no pressuposa ni que fa dos segles no se'n parlés ni que el seu conreu hagi començat fa tan poc temps.

La neologia com a pràctica és tan vella com la humanitat si n’observem una de les seves facetes més importants: la creativitat lèxica. És un fet inherent a l'espècie humana la capacitat de crear noves paraules per adaptar-se denominativament a la realitat o simplement referir-se a les coses, als pensaments i sentiments o als éssers humans d'una manera diferent a l'habitual pel simple plaer de cridar l'atenció o autoafirmar-se. La competència lèxica, dins de la competència lingüística en general, pressuposa un seguit de coneixements inherents al parlant pel simple fet de ser un ésser parlant. Són coneixements que van lligats a l'espècie humana.

Així, pel fet de formar part d'aquesta espècie, i pel que fa al lèxic, el parlant coneix paraules, les sap utilitzar canònicament (d'acord amb la fonètica, la morfologia, la sintaxi i la semàntica) $\mathrm{i}$ adequadament (usant-les en les situacions en què és previst d'utilitzar-les). Però, a més de conèixer una llista extensa de paraules de la llengua que li és pròpia, el parlant és capaç d'augmentar la llista de les unitats lèxiques que coneix amb noves incorporacions, ja sigui perquè les manlleva d'una altra llengua fent-les seves (usant-les en la seva forma originària o adaptant-les formalment a la llengua d'acollida), ja sigui construint-les a partir de les pautes que li facilita el sistema gramatical que té interioritzat. Aquesta capacitat és el que en lingüística s'anomena "creativitat lèxica». I cada una de les unitats novament construïdes és un neologisme. 
Els neologismes són unitats difícils de definir i encara més difícils de descriure holísticament. La raó d'aquesta dificultat rau en la seva pròpia naturalesa: es tracta d'unitats polièdriques, d'una banda, i d'unitats relatives, de l'altra. El Principi de poliedricitat (Cabré 2008: 9-36) i la idiosincràsia de la condició de «novetat» permeten explicar la complexitat d'ambdues característiques.

La poliedricitat és un principi inherent a tots els objectes de coneixement segons el qual tot fenomen és multidisciplinari i multidimensional. És multidisciplinari en el sentit que, ans d'esgotar la seva descripció dins d'una disciplina, es pot abordar des de matèries i camps de coneixement diferents, fet que suposa que, per descriure'l adequadament, cal situar-se en una perspectiva de descripció. És multidimensional perquè, fins i tot en l'interior d'una matèria d'abordatge determinada, presenta una diversitat de cares o aspectes de descripció de la totalitat dels quals no es pot donar compte simultàniament. Aquesta doble caracterització a partir del principi de poliedricitat justifica que presentem a continuació una sèrie diversa de vessants des dels quals es poden analitzar els neologismes.

La condició de relativitat dels neologismes és un altre dels obstacles que dificulten la seva definició precisa. Els neologismes són relatius per tal com la seva condició de «novetat» no és absoluta, sinó que cal remetre-la sempre a un punt de referència temporal, social, geogràfic, funcional $\mathrm{o}$ temàtic.

\section{LA NEOLOGIA EN EL SEU VESSANT PSICOLÒGIC}

No hi ha cap dubte que la capacitat de crear paraules noves actualitzant el cabal lèxic individual és una capacitat cognitiva que tenen tots els éssers humans. Per aquesta capacitat els parlants, amb independència de les característiques socials, polítiques i tipològiques de la llengua que parlen, són capaços de construir noves paraules posant en pràctica les regles de la gramàtica del lèxic, que poden ser de diferents tipus. És evident que aquesta capacitat és una capacitat cognitiva i gramatical que posseeixen els humans pel simple fet de pertànyer a la seva espècie.

Si bé la creativitat és un dels aspectes més rellevants de l'articulació de la neologia i la psicologia, no és l'únic. Els neologismes, com qualsevol unitat del lèxic, posseeixen característiques estructurals, lligades a la gramàtica, i característiques pragmàtiques, lligades a l'ús que en fem en situacions reals de comunicació, com veurem més endavant. En conseqüència, compleixen una sèrie de funcions: de representació (representen algun concepte), de comunicació (serveixen per transferir un contingut) i d'expressió (s'associen a valors sociopragmàtics diversos). 
Els valors pragmàtics associats a la producció, la recepció o la transmissió tenen sempre un objectiu: són projeccions de l'actitud de qui els produeix, causen impactes diversos en els qui els reben i se senten de diferent manera segons les situacions en què apareixen. Es tracta en tots els casos de factors d'ordre psicològic, que, pel que fa a l'emissor, busquen efectes diferents; i pel que fa al receptor o a la situació, produeixen efectes diferents.

Un parlant pot produir un neologisme per sorprendre, cridar l'atenció, reafirmar-se, adherir-se a algú o a alguna tendència, transgredir conscientment la canonicitat lèxica, etc. Aquestes actituds s'han descrit en termes de funcions dels neologismes des de la producció. Paral-lelament, un individu pot sentir-se estranyat, intrigat, confús, etc. en tant que receptor de neologismes produïts per altri: són funcions dels neologismes des de la recepció. Finalment, els neologismes poden tenir un relleu social més o menys gran en funció del tipus de neologisme i la situació en què es produeix: són funcions lligades a la situació o circulació dels neologismes.

\section{LA NEOLOGIA EN EL SEU VESSANT SOCIAL}

Les llengües són sistemes socials en un doble sentit: d'una banda, articulen els individus dels grups i els permeten diferenciar-se d'altres grups; de l'altra banda, reflecteixen a través del seu ús la visió que una determinada cultura té del món que l'envolta. El lèxic té un paper important en la discriminació social, és una de les peces clau de la representació de l'entorn per tal com la categorització de la realitat es duu a terme a través del lèxic.

En efecte, l'anàlisi de les unitats noves que apareixen en el lèxic d'una llengua és molt interessant per descriure l'evolució social i el grau d'adaptació d'una llengua als canvis que es produeixen. Ni que fos per aquesta única raó quedaria justificada la planificació lingüística, que inclou en les seves activitats la modernització del lèxic amb l'objectiu d'assegurar la plena disponibilitat d'una llengua per referir-se a totes les temàtiques, per cobrir totes les funcions i per adequar-se a tots els registres.

Així mateix, l'anàlisi dels neologismes, sobretot dels tipus de neologismes que es produeixen en una llengua, dóna marge també per interpretar el grau intern de vigor d'aquesta llengua i el nivell d'adhesió que mostren els seus parlants.

Finalment, la tria de llengües per part dels organismes internacionals constitueix un barem de la importància política diferent que es dóna a cada llengua. L'ús oficial d'una llengua en els contextos internacionals, i sobretot per part dels organismes 
internacionals, i, consegüentment, l'exclusió de determinades llengües d'aquests usos, és una mostra del grau de consideració institucional d'aquesta llengua. Figurar, doncs, en l'aparador de les llengües dels organismes oficials jerarquitza les llengües, però per ser-hi cal que aquesta llengua estigui desenvolupada en grau màxim a fi de poder fer possibles totes les funcions, bàsicament, formals, que la comunicació internacional requereix. L'activitat neològica sobre una llengua garanteix aquesta disponibilitat i actualització permanents.

\section{LA NEOLOGIA EN EL SEU VESSANT PRÀCTIC}

L'activitat neològica va conèixer un desenvolupament emergent a partir de la segona meitat del segle passat gràcies al progrés creixent de la traducció i la interpretació, i sobretot al moviment de reivindicació del multilingüisme. La necessitat de posseir recursos lèxics per a totes les funcions expressives i comunicatives i d'actualitzar-los de manera permanent a fi de servir eficaçment a les necessitats d'un món en permanent evolució, ha donat a l'activitat neològica un protagonisme important.

La modernització natural del lèxic d'una llengua, especialment en la producció de recursos de tema especialitzat, només es produeix en un context de creació de coneixement i d'innovació científica i tecnològica. Però si bé totes les llengües tenen recursos per expressar-ho tot, són les condicions polítiques i econòmiques de les societats que les usen els factors que determinen el seu grau de desenvolupament, raó per la qual les llengües de societats que, ans que produir, importen coneixement i tecnologia, si volen formar part del grup de llengües internacionalment actives, han de crear denominacions eficaces i prou estabilitzades per disposar d'equivalents per expressar totes les novetats. És per aquest motiu que l'activitat neològica planificada institucionalment o la produïda en el context de la traducció i la interpretació són del tot necessàries. Fruit d'aquesta necessitat és la gran quantitat de diccionaris de tema especialitzat i de bases de dades que hi ha i que s'han desenvolupat com a eines al servei de la traducció en tots els organismes internacionals multilingües. Un exemple il.lustratiu és el banc de dades IATE de la Unió Europea o el banc UNTERM de l'ONU.

És especialment destacable l'activitat neològica en temes d'especialitat que es duu a terme en un nombre important de comunitats i països en defensa de llengües poc esteses o en situació minoritzada. Una mostra d'això és el fet que hi hagi centres oficials de terminologia en totes les comunitats autònomes de l'Estat espanyol que no tenen el castellà com a llengua oficial. Aquesta activitat permanent de creació de nous 
termes per a nous conceptes és totalment imprescindible per a la modernització d'una llengua i el seu manteniment com a llengua de cultura especialitzada, particularment en els àmbits científics i tècnics.

Per completar el panorama dels contextos que requereixen activitat neològica, no es pot oblidar la necessitat de posar al dia els diccionaris generals de llengua, tant els monolingües com els bilingües, tant els destinats a adults com els destinats al públic escolar. Si una llengua evoluciona permanentment i el lèxic és el component que reflecteix de manera més explícita aquesta evolució, els diccionaris han d'adaptar-se a l'evolució introduint les noves unitats que han penetrat en l'ús dels parlants d'una comunitat, sempre que aquests usos estiguin prou consolidats i no contravinguin la imatge de futur que aquesta comunitat ha decidit que tingui la seva llengua. En conseqüència, la introducció de neologismes en els diccionaris és una tasca real imprescindible en lexicografia. Al costat de la seva funció de modernització de diccionaris, la neologia continguda en les obres lexicogràfiques, introduïdes a vegades de manera poc explícita o sense criteris prou sistemàtics, pot ser objecte d'anàlisi per treure conclusions sobre la representació de la norma en un diccionari o contrastar les diferents ideologies lingüístiques de diversos diccionaris.

Linterès de la neologia en el seu vessant pràctic ha donat lloc a una sèrie de projectes de recerca aplicats a la detecció $\mathrm{i}$ anàlisi de les unitats lèxiques noves que apareixen en el discurs públic, particularment a la premsa. Aquestes unitats de treball neològic han rebut el nom d'observatoris de neologia. Actualment hi ha observatoris de neologia en molts països europeus i americans, la pràctica totalitat dels quals s'han creat a partir de xarxes de neologia impulsades des del 1993 per l'Observatori de Neologia de la Universitat Pompeu Fabra de Barcelona (creat a la Universitat de Barcelona el 1989): la xarxa Neoxoc, que estudia la variació neològica en les diverses varietats geolectals del català; la xarxa Antenas, que recull i analitza els neologismes de l'espanyol d'Amèrica llatina i els contrasta amb els de l'espanyol de la península Ibèrica; la xarxa Neoroc per a les varietats de l'espanyol peninsular; i la xarxa Neorom (actualment quasi inactiva), creada per analitzar i contrastar la creació neològica en les diverses llengües romàniques.

L'Observatori de Neologia va néixer amb un propòsit molt concret: servir a l'actualització lexicogràfica catalana i castellana. És per aquesta raó que va basar-se metodològicament en la noció d' "exclusió lexicogràfica», segons la qual la condició de neologisme d'una unitat es determina pel fet de no ser en els diccionaris que conformen el corpus d'exclusió.

L'Observatori de Neologia de la UPF difon anualment la llista dels neologismes recollits a la premsa i a alguns mitjans audiovisuals a través del seu web d'accés lliure 
(www.iula.upf.edu/observatori) i del de dues institucions que donen suport al treball neològic: la Secció Filològica de l'Institut d'Estudis Catalans per als neologismes del català, i l'Instituto Cervantes per als neologismes del castellà. L'activitat de l'Observatori ha estat intensa en la convocatòria de seminaris i jornades d'estudi de la neologia i ha impulsat fins i tot un col.loqui internacional de neologia de les llengües romàniques, CINEO, del qual s'han fet dues edicions, la primera l'any 2008 a Barcelona, i la segona l'any zori a Sáo Paulo.

\section{NEOLOGIA I TECNOLOGIES}

El treball de detecció dels neologismes en el discurs, inicialment en el discurs escrit de la premsa, va començar com una activitat purament artesanal. Els qui el vam iniciar ara fa més de vint-i-cinc anys llegíem diàriament la premsa que havíem de buidar i hi assenyalàvem els possibles candidats a neologismes, primer servint-nos de la nostra pròpia competència lingüística $\mathrm{i}$, en segon lloc, confirmant que no apareixien amb el mateix sentit als diccionaris més habituals. No podem oblidar que es tractava de recollir les unitats que no apareixien en el corpus de diccionaris seleccionats com a punt de referència.

El desenvolupament de les tecnologies aplicades a les tasques lingüístiques va permetre anar més enllà del que suposava tenir emmagatzemats els neologismes en una base de dades de caràcter molt rudimentari. Els gestors de bases de dades relacionals van suposar un pas endavant en el treball neològic $i$ van permetre obrir al públic la consulta de la base de dades de neologismes de l'Observatori. Amb aquest pas es va poder accedir a la informació, no només per la forma del neologisme o pel fet de començar per, acabar amb o posseir una determinada cadena de caràcters, sinó també de recuperar tots els neologismes que complissin una o més d'una condició: període de temps, font on havia aparegut i tipus de neologisme. Aquesta possibilitat va obrir el pas a una gran quantitat de recerques descriptives i contrastives que es duen a terme any rere any en els diferents observatoris i que es difonen a través de comunicacions a congressos, seminaris i publicacions.

L'activitat neològica encara havia de fer dos passos més endavant en la utilització eficaç de les tecnologies: el primer pas el va representar la creació d'una plataforma web que integrava la cadena del treball neològic: selecció de documents per a la creació de corpus, detecció de candidats a neologisme, confirmació del caràcter neològic de les unitats detectades, emmagatzemament dels neologismes en format base de dades, incorporació automàtica de contextos i edició de les dades. La creació de la 
plataforma va fer possible la realitat i eficàcia del treball en xarxa $i$, per damunt de tot, una detecció molt més important de dades neològiques i més acurada pel que fa a la confirmació lexicogràfica del seu caràcter nou. Al mateix temps, la possibilitat de seleccionar els diccionaris que conformen el corpus d'exclusió lexicogràfica segons els casos va permetre matisar la condició neològica en funció de la varietat geolectal de les llengües, de forma que una unitat lèxica podia ser neològica en l'ús de l'espanyol d'Espanya, però no en l'ús de l'espanyol de Xile, posem per cas.

El darrer pas important en relació amb la tecnologia en el treball neològic el suposa la incorporació de sistemes cada cop més afinats de detecció automàtica de neologismes. Si bé a través de la plataforma ja es podien detectar automàticament els candidats a neologismes formals monolèxics, les línies de treball que hi ha avui dia iniciades permeten esperar que en poc temps els observatoris podran detectar neologismes formals polilèxics, neologismes sintàctics (per canvi de categoria gramatical) i neologismes semàntics.

\section{LA NEOLOGIA EN EL SEU VESSANT DISCIPLINAR}

La disciplinarització d'una matèria és el producte de la seva difusió social i de la concentració d'activitats i publicacions sobre el tema. La neologia va començar a ser reconeguda com a camp de treball i de reflexió amb una certa autonomia, sempre dins de la lexicologia, gràcies a l'activitat que es va dur a terme de manera continuada i sistemàtica al Quebec, tot i que les primeres activitats d'organització de la tasca neològica van ser impulsades des de França amb la intenció de recollir totes les varietats del francès contemporani al món francòfon. Van sorgir així els primers Observatoires du français contemporain empesos des de l'Institut National de la Langue Française (INALF) per Bernard Quemada.

Tot i així, va ser al Quebec que la neologia es va estabilitzar com a disciplina. La necessitat de promoure el francès con a llengua pròpia del Quebec en el context d'un Canadà constitucionalment bilingüe (actualment trilingüe) va empènyer els quebequesos a organitzar un procés de planificació estratègica dins el qual calia que la llengua francesa disposés de totes les unitats necessàries per expressar la modernitat, fins aleshores expressada en anglès, i a més fer-ho amb formes pròpies del francès del Quebec. L'Office de la langue française (actualment Office québécois de la langue française) va ser l'organisme que es va fer càrrec d'organitzar tota l'activitat lingüística i terminològica, una part de la qual, la més representativa, era fixar, i si calia crear, unitats en francès que poguessin substituir els anglicismes usats en els contextos d'especialitat. 
Així va iniciar-se una activitat neològica ingent que va posar la neologia en el mapa de les disciplines: col-loquis, seminaris universitaris, assignatures en els plans d'estudi de lingüística i traducció, publicacions, revistes, etc. La neologia posava així les bases de la seva consolidació disciplinar.

\section{LA NEOLOGIA EN EL SEU VESSANT TEÒRIC}

Moltes de les matèries que sorgeixen de la pràctica tenen dificultats per articular els seus fonaments teòrics. La neologia és un exemple prou clar d'aquest cas. Si bé l'activitat neològica és $\mathrm{i}$ ha estat intensa en els darrers cinquanta anys, la reflexió teòrica sobre els neologismes ha estat bastant minsa, i sobretot, molt repetitiva.

Alguns autors francesos de la dècada dels anys cinquanta, seixanta i setanta del segle passat són el punt de partida des del qual s'han configurat les bases de la neologia com a camp de reflexió. D'entre tots ells destaquen els noms i l'obra de Louis Guilbert i Alain Rey.

No voldríem deixar entendre que fora d'aquests noms no s'hagi escrit, i molt, sobre neologia; ni tampoc que tot el que s'hagi escrit sigui pura repetició del que aquests autors van dir. El que volem dir és que la majoria dels treballs de neologia fets darrerament són treballs descriptius i contrastius restringits a una llengua o a diverses, però molt pocs autors donen pautes perquè la neologia avanci com a camp de coneixement. Jean-Claude Boulanger i Jean-François Sablayrolles són alguns d'aquests pocs especialistes que han aportat idees noves al cos teòric de la neologia.

Un dels principals obstacles en la construcció d'un camp de coneixement centrat en la neologia és la definició del seu objecte d'estudi, i sobretot la falta d'estabilització d'aquest objecte. En efecte, les unitats absolutament noves, noves per a tothom, en tots els contextos i en totes les situacions, són extremadament rares. La neologia porta inherent el seu caràcter temporal (allò que és un neologisme en un moment donat deixa de ser-ho) i subjectiu (allò que és un neologisme per algú, en algun lloc o en un determinat context d'ús pot no ser-ho per a un altre parlant, àmbit geogràfic o context de comunicació). Podem imaginar, doncs, com és de difícil de construir un camp de coneixement centrat en un objecte relatiu i abordar-lo amb una metodologia científica, que requereix com a primer pas precisar molt bé l'objecte que ens proposem d'observar.

Alain Rey (1976: 3-17) la que, segons la meva opinió, és la definició més encertada del que és un neologisme: «unité nouvelle de nature lexicale dans un code linguistique défini». Aquesta formulació és prou explícita per fer-nos observar que els neologismes en tant que objectes de coneixement són unitats relatives que només 
es poden reconèixer si ens situem en un període de temps, situació discursiva o perspectiva enunciativa precisos.

La consolidació, doncs, de la neologia en tant que camp de coneixement orientat a l'observació, la descripció i l'explicació dels neologismes requereix dels especialistes una intensa reflexió sobre les característiques de l'objecte d'estudi de la neologia i les vies per abordar la descripció d'aquest objecte, tenint en compte que es tracta d'un objecte polièdric, i per tant multidimensional i mutidisciplinari, però, a més, atès que es tracta d'un objecte relatiu que demana que l'analista se situï en una determinada perspectiva per poder-ne fer un abordatge pertinent $\mathrm{i}$ adequat.

Els neologismes són objectes multidisciplinaris en el sentit que formen part de camps de saber diferents, en cada un dels quals es privilegia algun dels seus valors, característiques o funcions per damunt d'altres, com hem vist al llarg d'aquest article. La neologia concerneix tant les matèries que formen part de les ciències cognitives, com les que integren les ciències socials i de les ciències del llenguatge.

Els neologismes són objectes multidimensionals perquè, fins i tot dins d'una mateixa perspectiva, despleguen diverses facetes d'anàlisi. En la perspectiva de la lingüística, la condició de neologicitat d'una unitat pot afectar la forma, el sentit, la classe gramatical o les condicions pragmàtiques.

Aquesta multiplicitat de factors i perspectives complica extraordinàriament la construcció d'una teoria orientada als neologismes que sigui capaç de donar-ne compte d'una manera adequada i global. Tot i així, seguint alguns dels principis que, segons la nostra perspectiva, ens van servir per desenvolupar una teoria dels neologismes, la teoria comunicativa de la terminologia (TCT), hem pogut aillar una sèrie de criteris que permetrien abordar els neologismes sense perdre de vista la seva complexitat. Aquests principis, que llistem a continuació, han estat objecte d'una reflexió més acurada a Cabré (2015).

El primer principi, del qual ja hem parlat, és el principi de poliedricitat, segons el qual tot objecte de coneixement, i els neologismes no en són cap excepció, és multidisciplinari i multidimensional.

El principi de descripció situada vol donar raó del fet que una descripció dels neologismes requereix que l'analista se situï en una perspectiva determinada dins de la qual sigui capaç de donar compte d'una faceta determinada d'aquest objecte, sense contradir-se amb la descripció que es duu a terme des de les altres perspectives. Aquesta condició d'articulació entre les diverses descripcions situades l'hem anomenada principi de no contradicció. 
El principi de descripció orientada, que es basa en el criteri de multifuncionalitat dels objectes de coneixement, pretén donar raó del fet que cada perspectiva de descripció persegueix uns objectius diferents i que, en el cas de la descripció neològica, s'ha d'explicitar en funció de quines metes es duu a terme.

Un cinquè principi, el Principi d'explicitació, ens obliga a precisar quins aspectes dels neologismes descrivim, per exemple, cal indicar si s'analitza un conjunt de neologismes en sincronia o l'evolució d'un o més neologismes en diacronia. Situats en la sincronia, són pertinents nocions com la de predictibilitat, productivitat, disponibilitat, freqüència, memorització, etc. de les unitats neològiques. Situats en diacronia, els factors interns dels neologismes cedeixen protagonisme als factors socials i psicològics.

El principi de focalització sobre l'objecte es proposa assegurar que en una descripció s'expliciti quina part de l'objecte es considera la més rellevant. Per exemple, cal aclarir si s'analitza la corba evolutiva d'un conjunt d'unitats noves i es posa èmfasi en la memorització social d'aquestes unitats o bé en les característiques que les fan diccionaritzables.

El principi del punt de vista o principi de la perspectiva vol assegurar que, atesa la naturalesa enunciativa dels neologismes, s'expliciti en cada descripció des de quin vessant del procés enunciatiu actuem: des de la producció de neologismes, des de la recepció o des de la transmissió. Només si tenim en compte aquest principi podem explicitar què entenem per "neologicitat» aplicada a una unitat concreta, o més encara, la noció de "graus de neologicitat», que ens duu a dir que una unitat pot ser "més neològica que una altra». Des de la producció la noció de neologicitat és discreta, tot i que pot ser conscient o inconscient, voluntària o involuntària. Des de la recepció la neologicitat és gradual perquè es tradueix en el grau d'impacte que una unitat nova té en el receptor.

Finalment, per articular aquesta llarga llista de principis, cal un principi integrador, que anomenem principi d'interrelació entre situació, dimensió, focalització, orientació $i$ perspectiva, que estructuri i articuli adequadament i jeràrquicament aquest conjunt de principis que no pretenen altra cosa que donar elements per a la construcció d'una teoria dels neologismes i ajudar així a la consolidació de la neologia com un camp de coneixement estructurat.

\author{
M. Teresa Cabré Castellví \\ Universitat Pompeu Fabra (Barcelona) \\ teresa.cabre@upf.edu
}




\section{REFERÈNCIES BIBLIOGRÀFIQUES}

Cabré Castellyví, M. Teresa (2008) «El principio de poliedricidad o la articulación de lo discursivo, lo cognitivo y lo lingüístico en Terminología", Ibérica, I (I6), pp. 9-36.

- (2015) «Bases para una teoría de los neologismos léxicos: primeras reflexiones», dins Ieda Maria Alves \& Eliane Simôes Pereira (eds.), Neologia das línguas românicas, São Paulo, Humanitas, pp. 79-IO7.

ReY, Alain (1976) «Néologisme, un pseudoconcept?», Cahiers de Lexicologie, 28, pp. 3-17 